\title{
TI.62.1
}

\section{User Perspectives of Diagnostics - A Multidimensional View}

- PDF: perspectives.pdf

- Text: perspectives.txt

\section{More Information}

\begin{tabular}{|l|l|}
\hline Repository ID & TI.62.1 \\
\hline Persistent URL & http://doi.org/10.26869/TI.62.1 \\
\hline Title & User Perspectives of Diagnostics - A Multidimensional View \\
\hline Authors & Unknown \\
\hline Sponsor & Carnegie Mellon University, Internet2, and the NSF Middleware Initiative \\
\hline Review & \\
\hline Status & Legacy \\
\hline Publish Date & $2005(?)$ \\
\hline DOI & $10.26869 / T I .62 .1$ \\
\hline Signature & \\
\hline Deprecated & No \\
\hline Future Review & \\
\hline Supersedes & \\
\hline Format & PDF, Text \\
\hline Related Docs & \\
\hline Development Location & \\
\hline IP Framework & \\
\hline Subject Tags & middlewarerescue \\
\hline Notes & \\
\hline & \\
\hline
\end{tabular}

